Disponível em

http://www.anpad.org.br/rac

RAC, Rio de Janeiro, v. 18, n. 4, art. 3, pp. 416-445, Jul./Ago. 2014

http://dx.doi.org/10.1590/1982-7849rac20141110

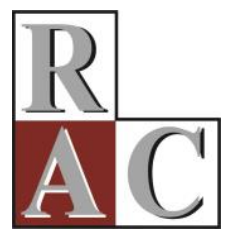

$(\mathrm{cc})$ EY-NO

\title{
Modos de Entrada no Investimento Direto no Exterior: Um Estudo da Literatura Empírica
}

Foreign Direct Investment Entry Modes: A Study of the Empirical Literature

Augusto Cesar Arenaro e Mello Dias

E-mail: augustoarenaro@yahoo.com.br Pontifícia Universidade Católica do Rio de Janeiro - PUC Rua Marquês de São Vicente, 225, 22451-900, Gávea, Rio de Janeiro, RJ, Brasil.

Angela Maria Cavalcanti da Rocha

E-mail: angelarocha@iag.puc-rio.br Pontifícia Universidade Católica do Rio de Janeiro - PUC Rua Marquês de São Vicente, 225, 22451-900, Gávea, Rio de Janeiro, RJ, Brasil.

Jorge Ferreira da Silva

E-mail: shopshop@iag.puc-rio.br

Pontifícia Universidade Católica do Rio de Janeiro - PUC Rua Marquês de São Vicente, 225, 22451-900, Gávea, Rio de Janeiro, RJ, Brasil. 


\title{
Resumo
}

Este trabalho é uma revisão de estudos empíricos, de cunho quantitativo, no contexto da literatura internacional, sobre modos de entrada no mercado externo por meio de capital próprio, utilizados por empresas manufatureiras. O trabalho sintetiza e avalia a contribuição dos estudos existentes a respeito, assim, identificando o conhecimento acumulado no período de 1990 a 2011 quanto aos antecedentes da decisão de modos de entrada no investimento direto no exterior e o impacto dos modos de entrada escolhidos sobre o desempenho, de modo a prover os pesquisadores com um conjunto de sugestões que lhes permita construírem seus estudos de forma mais efetiva no tocante ao conhecimento existente.

Palavras-chave: modo de entrada; nível de propriedade; forma de estabelecimento; tipo de atividade; investimento direto no exterior.

\begin{abstract}
This work is a review of quantitative empirical studies extracted from the international literature on equity entry modes used by manufacturing companies in foreign markets. The work synthesizes and evaluates the contribution of the extant literature on the topic, and identifies the cumulative knowledge from the 1990-2011 period concerning the antecedents to foreign direct investment entry-mode decisions and the impact these entry modes have on subsidiary performance, in order to offer researchers a set of suggestions to more effectively build their studies based on existing knowledge.
\end{abstract}

Key words: entry mode; ownership level; establishment mode; activity type; foreign direct investment. 


\section{Introdução}

Uma das questões centrais na literatura de negócios internacionais é a decisão de modos de entrada por empresas multinacionais (EMNs) em mercados externos. Embora a literatura de negócios internacionais seja bastante rica em estudos sobre o tema, a maior parte dos estudos provém de países desenvolvidos. Apenas recentemente, as pesquisas a respeito dos modos de entrada têm-se voltado para multinacionais de países emergentes (por exemplo, Cui, Jiang, \& Stening, 2011; Tseng \& Lee, 2010). Mesmo assim, essas pesquisas têm privilegiado empresas originárias de países asiáticos, sendo praticamente inexistentes estudos empíricos com grandes amostras sobre as decisões de modo de entrada de empresas sul-americanas e, em particular, brasileiras.

Apesar da relevância do tema, não foram identificadas revisões de literatura sobre a questão da escolha de modos de entrada com capital próprio (investimento direto no exterior). No entanto o esforço de síntese do conhecimento já existente sobre o tema pode auxiliar os pesquisadores a melhor estruturarem futuros estudos que abordem as questões que permanecem em aberto e, assim, evitem caminhos já percorridos ou que se mostrem pouco promissores. Além disso, revisões de literatura ajudam os pesquisadores em suas escolhas conceituais, de construtos e de indicadores para estes.

Sob tal perspectiva, o presente trabalho caracteriza-se como uma revisão dos estudos empíricos, de cunho quantitativo, publicados entre 1990 e 2011, em âmbito internacional, sobre modos de entrada utilizados no investimento direto no exterior. O estudo tem como objetivos: (a) sintetizar a literatura existente sobre o tema, identificando antecedentes da decisão de modos de entrada no investimento direto no exterior e o impacto dos modos de entrada escolhidos sobre o desempenho; (b) mensurar os resultados obtidos pelos estudos realizados em seu conjunto, em termos do conhecimento gerado sobre as decisões de modos de entrada; (c) avaliar se o conjunto de resultados obtidos na literatura pode ser útil ao entendimento das decisões de modos de entrada de EMNs brasileiras; e (d) prover os pesquisadores com um conjunto de sugestões emanadas da revisão da literatura que lhes permita construir seus estudos de forma mais efetiva, sobre o conhecimento existente.

\section{Natureza e Decisões Relativas aos Modos de Entrada}

O modo de entrada no mercado externo é um arranjo institucional que torna possível o ingresso de produtos, tecnologia, habilidades humanas, gestão ou outros recursos de uma empresa em um país estrangeiro (Root, 1994).

De acordo com uma perspectiva econômica, a empresa pode planejar sua entrada no mercado externo de duas formas (Katsikeas, Leonidou, \& Samiee, 2009). Primeiro, ela pode exportar seus produtos para o país-alvo a partir de uma base de produção fora daquele país. Segundo, ela pode transferir seus recursos em tecnologia, capital e habilidades humanas para o país estrangeiro, onde podem ser vendidos diretamente para os usuários finais ou combinados com recursos locais (principalmente trabalho) para a fabricação de produtos para venda naquele mercado. Sob uma perspectiva gerencial/operacional, essas duas formas de entrada podem ser divididas em vários modos distintos, os quais oferecem diferentes custos e benefícios para as empresas multinacionais.

Root (1994) classifica esses modos de entrada em três grandes grupos: exportações, arranjos contratuais e investimentos diretos. Exportações diferem dos outros dois modos de entrada básicos pelo fato de o produto final ou intermediário de uma empresa ser fabricado fora do país-alvo e, posteriormente, transferido para ele (Cavusgil, Knight, \& Riesenberg, 2010; Rocha \& Almeida, 2006). Arranjos contratuais são associações de longa duração entre uma empresa e uma entidade no país-alvo que envolvem transferência de tecnologia ou know-how, sem utilização de capital próprio da empresa (Root, 1994). 
Investimentos diretos envolvem a propriedade por uma empresa multinacional (EMN) de plantas fabris ou outras unidades de produção no país-alvo (Root, 1994). Sobre a etapa de produção, essas subsidiárias podem variar desde simples plantas de montagem, que dependem inteiramente de importações de produtos intermediários da empresa-mãe, até plantas que realizam a fabricação completa de um produto. Em termos de propriedade e controle da gestão (que é a característica distintiva deste modo de entrada), as subsidiárias de produção no exterior podem ser classificadas como empreendimentos individuais (sole ventures), com propriedade e controle pleno por parte da empresamãe (subsidiárias de controle integral), ou como empreendimentos conjuntos (joint ventures), em que a propriedade e o controle são compartilhados com um ou mais parceiros locais. Uma EMN pode iniciar um empreendimento individual no país-alvo a partir de investimento greenfield ou por meio da aquisição de empresa local (Dikova \& Brouthers, 2009; Hennart \& Park, 1993).

Baseados no trabalho de Kumar e Subramaniam (1997), Pan e Tse (2000) postulam que a escolha do modo de entrada pode ser analisada a partir de uma perspectiva hierárquica. Inicialmente, os gestores estruturam vários modos de entrada em uma hierarquia multinível e definem um conjunto de critérios de avaliação para cada nível. O primeiro nível da hierarquia refere-se aos modos de entrada sem e com capital próprio. Feita essa primeira escolha, os gestores, em uma segunda etapa, decidem que modo específico, dentro da alternativa escolhida, deve ser adotado.

Para Hennart (1988), a principal diferença entre uma subsidiária de controle integral (em inglês, wholly owned subsidiary, ou WOS) e uma joint-venture (JV) reside no método escolhido para remunerar os parceiros. A característica fundamental do capital próprio, seja ele compartilhado em uma JV ou integral em uma WOS, é que os parceiros são remunerados ex-post, a partir dos lucros do empreendimento, em contraste com os arranjos contratuais, em que os pagamentos são especificados ex-ante. A única diferença entre eles, portanto, reside no fato de que as JVs implicam uma internalização conjunta, enquanto as WOSs representam uma internalização individual.

Brouthers e Hennart (2007) adotam a posição de que as JVs podem incluir tanto investimentos greenfield compartilhados quanto aquisições parciais. Ou seja, são necessárias decisões distintas sobre o nível de propriedade (JV versus WOS) e a forma de estabelecimento (investimento greenfield versus aquisição). Esta visão foi testada, empiricamente, por Ruiz-Moreno, Mas-Ruiza e Nicolau-Gonzálbez (2007), que confirmaram a existência de um processo decisório em dois estágios, em que a escolha do nível de propriedade precede a escolha da forma de estabelecimento.

Uma terceira importante decisão em relação ao modo de entrada refere-se à escolha do tipo de atividade que a empresa exercerá no mercado externo. Essa escolha, entretanto, tem recebido pouca atenção na literatura acadêmica (Buckley \& Casson, 1998), fato este que pode ser explicado, pelo menos em parte, pela carência de dados adequados para a realização de estudos empíricos (Kleinert \& Toubal, 2010). Em um dos poucos estudos que tratam do tipo de atividade em pesquisas relacionadas a modos de entrada no mercado externo, Pla-Barber (2001) realiza análises distinguindo entre subsidiárias de vendas e de produção. Buckley e Casson (1998), por sua vez, abordam a escolha do modo de entrada entre instalações de distribuição e de produção, enquanto Bell (1996) testa, empiricamente, três tipos de atividades no exterior: marketing e vendas, pesquisa e desenvolvimento $(\mathrm{P} \& \mathrm{D})$ e produção. A Figura 1 apresenta a concepção dos autores desta revisão de literatura da hierarquia de decisões no que se refere a modos de entrada envolvendo capital próprio. 


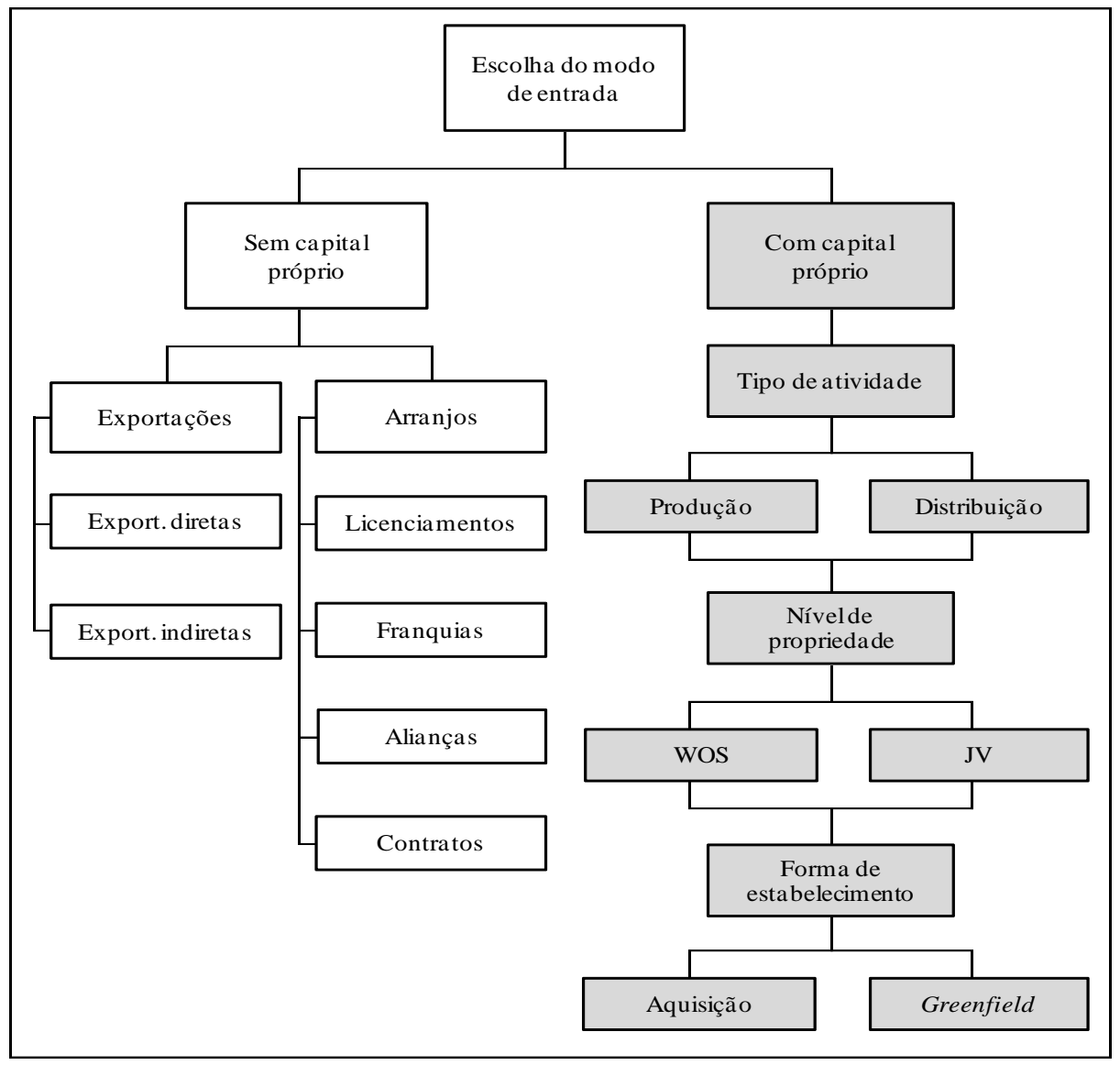

Figura 1. Hierarquia das Decisões de Modo de Entrada no Mercado Externo. As células sombreadas referem-se ao escopo do presente estudo. Fonte: Elaboração dos autores a partir da literatura.

\section{Metodologia}

Este trabalho é uma revisão de literatura sobre modos de entrada com capital próprio de empresas manufatureiras em mercados externos. Segundo Fink (2005), uma revisão de literatura sintetiza a literatura existente a respeito de determinado tema, dessa maneira, comparando os resultados obtidos de diferentes estudos com o intuito de apresentar o estado da arte sobre certo assunto e ressaltar possíveis oportunidades de realização de novos estudos.

A definição do foco da revisão da literatura é o primeiro passo nesse processo. No presente estudo, além da definição do objeto da revisão de literatura (modos de entrada com capital próprio de empresas manufatureiras em mercados externos), foram adotados os seguintes critérios para delimitar o escopo da revisão de literatura realizada:

- Tratar-se de estudo empírico utilizando amostras da população de multinacionais em um ou mais países de origem;

- Serem estudos cross-sectional, assim, eliminando-se estudos qualitativos e longitudinais por utilizarem metodologias bastante distintas;

- Ter data de publicação entre 1990 e 2011 (a primeira data foi estabelecida como corte e a segunda data se deve em razão de que o levantamento de artigos foi realizado em 2012); 
Abordar modos de entrada por meio de capital próprio (ou seja, foram excluídos os modos de entrada sem capital próprio, como exportações e licenciamento, que apresentam características bastante distintas);

Analisar empresas manufatureiras, uma vez que os modos de entrada de empresas de serviços e do agronegócio diferem substancialmente do de empresas manufatureiras;

- Identificar claramente os países de origem dos investimentos (critério necessário para estabelecer se trata-se de empresas provenientes de países desenvolvidos ou emergentes);

- Não confundir os níveis de decisão previamente indicados (nível de propriedade, forma de estabelecimento e tipo de atividade), pois, quando isso ocorre, não se pode estabelecer com clareza os impactos das variáveis antecedentes, nem o impacto dos modos de entrada sobre o desempenho. seguir.

A seleção dos estudos para a presente revisão de literatura seguiu o procedimento descrito a

Em primeiro lugar, foram selecionados estudos empíricos em 12 periódicos internacionais qualificados, que tratavam especificamente de modos de entrada em mercados externos. Os periódicos internacionais analisados foram: Academy of Management Journal; International Business Review; International Marketing Review; Journal of Business Research; Journal of International Business Studies; Journal of International Management; Journal of International Marketing; Journal of Management; Journal of Management Studies; Journal of World Business; Management International Review; Strategic Management Journal.

Em segundo lugar, foi desenvolvida uma busca em diversas bases nacionais e internacionais (Ebsco, Emerald, Jstor, Scielo, Science Direct e Wilson), a partir de um conjunto de palavras-chave consideradas relevantes. Tanto a seleção dos periódicos quanto a escolha das palavras-chave foram executadas com o auxílio de três especialistas em negócios internacionais, tendo sido também considerados os fatores de impacto dos periódicos. Este levantamento levou a um total de cerca de 600 artigos, que, então, passaram por um screening inicial, que consistiu na leitura do resumo para verificar se o trabalho realmente se enquadrava no tema da revisão de literatura pretendida.

Por derradeiro, foram selecionados unicamente os artigos que obedeciam aos critérios inicialmente definidos, com o propósito de obter certa homogeneidade nos estudos analisados.

Desse modo, foram identificados 82 estudos empíricos que atendiam a esses critérios, sendo que 52 deles tratam exclusivamente da escolha do modo de entrada, 27 tratam da relação entre modo de entrada e desempenho da subsidiária internacional e três tratam dos dois temas de forma conjunta. Do total de artigos selecionados, apenas 15 (19\%) apresentam uma economia emergente como país de origem das EMNs. Na Tabela 1, relacionam-se os estudos que tratam da escolha do modo de entrada; e, na Tabela 2, os estudos que tratam da relação entre modo de entrada e desempenho da subsidiária internacional. O desempenho da subsidiária internacional é medido de diferentes formas nos artigos revisados.

Com relação aos países de origem e destino das empresas nos estudos revisados (colunas 4 e 5 nas Tabelas 1 e 2), cabe observar que, embora o país de origem apareça sempre nos estudos analisados, nem sempre são identificados quais são os países de destino dos investimentos no exterior, particularmente, porque é frequente que sejam muitos. Assim, em alguns casos, os autores não discriminam, ou simplesmente informam que são países desenvolvidos e/ou em desenvolvimento. 
Tabela 1

Estudos Empíricos sobre Modos de Entrada com Capital Próprio em Mercados Externos

\begin{tabular}{|c|c|c|c|c|c|}
\hline $\mathbf{N}^{\circ}$ & Artigo & Amostra & $\begin{array}{l}\text { País/Região de } \\
\text { Origem }\end{array}$ & $\begin{array}{l}\text { País/Região de } \\
\text { Destino }\end{array}$ & $\begin{array}{c}\text { Modo de } \\
\text { Entrada } \\
\text { Estudado }\end{array}$ \\
\hline 1 & Zejan (1990) & 250 & Suécia & NI (30 países) & $\mathrm{FE}$ \\
\hline 2 & Hennart (1991) & 158 & Japão & EUA & NP \\
\hline 3 & Hennart e Park (1993) & 270 & Japão & EUA & $\mathrm{FE}$ \\
\hline 4 & Agarwal (1994) & 148 & EUA & PD + EE (20 países) & NP \\
\hline 5 & Andersson e Svensson (1994) & 925 & Suécia & $\mathrm{PD}+\mathrm{EE}$ & $\mathrm{FE}$ \\
\hline 6 & Cho e Padmanabhan (1995) & 756 & Japão & NI (45 países) & $\mathrm{FE}$ \\
\hline 7 & Bell (1996) & 168 & Holanda & PD + EE (40 países) & NP \\
\hline 8 & Benito (1996) & 174 & Noruega & NI & NP \\
\hline 9 & Padmanabhan e Cho (1996) & 839 & Japão & PD + EE (36 países) & NP \\
\hline 10 & Cleeve (1997) & 112 & Japão & Reino Unido & NP \\
\hline 11 & $\begin{array}{l}\text { Erramilli, Agarwal e Kim } \\
\text { (1997) }\end{array}$ & 177 & Coreia do Sul & $\mathrm{PD}+\mathrm{EE}$ & NP \\
\hline 12 & Barkema e Vermeulen (1998) & 829 & Holanda & $\mathrm{PD}+\mathrm{EE}$ & $\mathrm{FE}$ \\
\hline 13 & Hennart e Larimo (1998) & 401 & Finlândia; Japão & EUA & NP \\
\hline 14 & Madhok (1998) & 130 & $\begin{array}{l}\text { América do Norte; } \\
\text { Europa }\end{array}$ & NI & NP \\
\hline 15 & Mutinelli e Piscitello (1998) & 947 & Itália & $\mathrm{PD}+\mathrm{EE}$ & NP \\
\hline 16 & Delios e Beamish (1999) & 1.424 & Japão & Ásia & $\mathrm{NP}$ \\
\hline 17 & Padmanabhan e Cho (1999) & 752 & Japão & NI (45 países) & $\mathrm{NP}+\mathrm{FE}$ \\
\hline 18 & Brouthers e Brouthers (2000) & 136 & Japão & Europa Ocidental & $\mathrm{FE}$ \\
\hline 19 & Lin (2000) & 251 & Japão & China & NP \\
\hline 20 & Makino e Neupert (2000) & 131 & EUA & Japão & NP \\
\hline 21 & Rajan e Pangarkar (2000) & 83 & Cingapura & PD + EE (18 países) & NP \\
\hline 22 & Brouthers e Brouthers (2001) & 231 & $\begin{array}{c}\text { Alemanha; EUA; } \\
\text { Holanda; Reino Unido }\end{array}$ & $\begin{array}{l}\text { Europa Central e } \\
\text { Oriental }\end{array}$ & NP \\
\hline 23 & Cho e Padmanabhan (2001) & 455 & Japão & NI (45 países) & NP \\
\hline 24 & Shi, Ho e Siu (2001) & 218 & Hong Kong & China & NP \\
\hline 25 & Anand e Delios (2002) & 2.175 & $\begin{array}{l}\text { Alemanha; Japão; } \\
\text { Reino Unido }\end{array}$ & EUA & $\mathrm{FE}$ \\
\hline 26 & Brouthers (2002) & 156 & União Europeia & NI (27 países) & NP \\
\hline 27 & S.-F. S. Chen e Hennart (2002) & 269 & Japão & EUA & NP \\
\hline 28 & Harzing (2003) & 287 & $\begin{array}{c}\text { Alemanha; EUA; } \\
\text { Finlândia; França; } \\
\text { Holanda; Japão; Reino } \\
\text { Unido; Suécia; Suíça }\end{array}$ & PD + EE (22 países) & $\mathrm{FE}$ \\
\hline
\end{tabular}




\section{Tabela 1 (continuação)}

\begin{tabular}{|c|c|c|c|c|c|}
\hline $\mathbf{N}^{\circ}$ & Artigo & Amostra & $\begin{array}{l}\text { País/Região de } \\
\text { Origem }\end{array}$ & $\begin{array}{l}\text { País/Região de } \\
\text { Destino }\end{array}$ & $\begin{array}{l}\text { Modo de } \\
\text { Entrada } \\
\text { Estudado }\end{array}$ \\
\hline 29 & $\mathrm{Lu}(2002)$ & 1.194 & Japão & PD (12 países) & $\mathrm{NP}$ \\
\hline 30 & Tsai e Cheng (2002) & 105 & Taiwan & EUA & NP \\
\hline 31 & Yiu e Makino (2002) & 364 & Japão & PD + EE (23 países) & NP \\
\hline 32 & $\begin{array}{l}\text { Brouthers, Brouthers e Werner } \\
(2003)\end{array}$ & 218 & $\begin{array}{l}\text { Alemanha; Holanda; } \\
\text { Reino Unido }\end{array}$ & $\begin{array}{l}\text { Europa Central e } \\
\text { Oriental }\end{array}$ & NP \\
\hline 33 & Guillén (2003) & 170 & Coreia do Sul & China & NP \\
\hline 34 & Larimo (2003) & 3.524 & $\begin{array}{l}\text { Dinamarca; Finlândia; } \\
\text { Noruega; Suécia }\end{array}$ & PD+EE (71 países) & $\mathrm{FE}$ \\
\hline 35 & S.-F. S. Chen e Zeng (2004) & 269 & Japão & EUA & $\mathrm{FE}$ \\
\hline 36 & Pak e Park (2004) & 3.236 & Japão & NI & $\mathrm{NP}$ \\
\hline 37 & Tsai e Cheng (2004) & 188 & Taiwan & $\mathrm{PD}+\mathrm{EE}$ & $\mathrm{NP}+\mathrm{EE}$ \\
\hline 38 & Xu, Pan e Beamish (2004) & 2.339 & Japão & PD + EE (44 países) & $\mathrm{NP}$ \\
\hline 39 & Cho e Padmanabhan (2005) & 604 & Japão & NI (45 países) & NP \\
\hline 40 & Drogendijk e Slangen (2006) & 246 & Holanda & NI & $\mathrm{FE}$ \\
\hline 41 & Dikova e Witteloostuijn (2007) & 160 & União Europeia & $\begin{array}{l}\text { Europa Central e } \\
\text { Oriental }\end{array}$ & $\mathrm{NP}+\mathrm{FE}$ \\
\hline 42 & $\begin{array}{l}\text { Brouthers, Brouthers e Werner } \\
\text { (2008) }\end{array}$ & 232 & $\begin{array}{l}\text { Alemanha; EUA; } \\
\text { Grécia; Holanda }\end{array}$ & $\begin{array}{l}\text { Europa Central e } \\
\text { Oriental }\end{array}$ & NP \\
\hline 43 & $\begin{array}{l}\text { Demirbag, Tatoglu e Glaister } \\
\text { (2008) }\end{array}$ & 145 & $\begin{array}{l}\text { Alemanha; Áustria; } \\
\text { Bélgica; Canadá; } \\
\text { Dinamarca; EUA; } \\
\text { Finlândia; França; } \\
\text { Holanda; Itália; Japão; } \\
\text { Noruega; Reino } \\
\text { Unido; Suécia; Suíça }\end{array}$ & Turquia & $\mathrm{FE}$ \\
\hline 44 & Slangen e Hennart (2008a) & 171 & Holanda & PD + EE (35 países) & $\mathrm{FE}$ \\
\hline 45 & Wang e Schann (2008) & 4.558 & Japão & NI & NP \\
\hline 46 & Cui e Jiang (2009) & 138 & China & $\mathrm{PD}+\mathrm{EE}$ & NP \\
\hline 47 & $\begin{array}{l}\text { Demirbag, Tatoglu e Glaister } \\
\text { (2009) }\end{array}$ & 522 & Turquia & $\mathrm{PD}+\mathrm{EE}$ & NP \\
\hline 48 & Dow e Larimo (2009) & 1.502 & $\begin{array}{l}\text { Dinamarca; Finlândia; } \\
\text { Noruega; Suécia }\end{array}$ & PD + EE (50 países) & NP \\
\hline 49 & Slangen e Tulder (2009) & 231 & Holanda & PD + EE (48 países) & $\mathrm{NP}$ \\
\hline 50 & Brouthers e Dikova (2010) & 154 & Europa Ocidental & $\begin{array}{l}\text { Europa Central e } \\
\text { Oriental }\end{array}$ & $\mathrm{FE}$ \\
\hline 51 & Chiao, Lo e Yu (2010) & 819 & Taiwan & China & $\mathrm{NP}$ \\
\hline 52 & $\begin{array}{l}\text { Demirbag, McGuiness e Altay } \\
\text { (2010) }\end{array}$ & 104 & Turquia & Ásia Central & $\mathrm{NP}$ \\
\hline
\end{tabular}




\section{Tabela 1 (continuação)}

\begin{tabular}{llcccc}
\hline $\mathbf{N}^{\circ}$ & \multicolumn{1}{c}{ Artigo } & Amostra & $\begin{array}{c}\text { País/Região de } \\
\text { Origem }\end{array}$ & $\begin{array}{c}\text { País/Região de } \\
\text { Destino }\end{array}$ & $\begin{array}{c}\text { Modo de } \\
\text { Entrada } \\
\text { Estudado }\end{array}$ \\
\hline 53 & $\begin{array}{l}\text { López-Duarte e Vidal-Suárez } \\
(2010)\end{array}$ & 334 & Espanha & PD + EE (34 países) & NP \\
54 & Tseng e Lee (2010) & 84 & Taiwan & PD + EE & NP \\
55 & Cui, Jiang e Stening (2011) & 138 & China & NI & NP \\
\hline
\end{tabular}

Nota. As células sombreadas referem-se a estudos de EMNs oriundas de economias emergentes.

Legendas: NI = não identificado; $\mathrm{PD}=$ países desenvolvidos; $\mathrm{EE}=$ economias emergentes; $\mathrm{NP}=$ nível de propriedade (subsidiária própria vs joint venture); $\mathrm{FE}=$ forma de estabelecimento (investimento greenfield ou aquisição).

Tabela 2

Estudos Empíricos Relacionando Modos de Entrada e Desempenho da Subsidiária Internacional

\begin{tabular}{|c|c|c|c|c|c|}
\hline $\mathbf{N}^{\circ}$ & Artigo & Amostra & $\begin{array}{l}\text { País/Região de } \\
\text { Origem }\end{array}$ & $\begin{array}{l}\text { País/Região de } \\
\text { Destino }\end{array}$ & $\begin{array}{c}\text { Modo de } \\
\text { Entrada } \\
\text { Estudado }\end{array}$ \\
\hline 56 & Li e Guisinger (1991) & 85 & $\begin{array}{l}\text { Alemanha; Bélgica; } \\
\text { Canadá; França; } \\
\text { Holanda; Japão; Reino } \\
\text { Unido; Suécia; Suíça }\end{array}$ & EUA & $\mathrm{FE}$ \\
\hline 57 & Chowdhury (1992) & 8.741 & EUA & NI & NP \\
\hline 58 & $\begin{array}{l}\text { Pennings, Barkema e Douma } \\
\text { (1994) }\end{array}$ & 462 & Holanda & NI & $\mathrm{NP}+\mathrm{FE}$ \\
\hline 59 & $\begin{array}{l}\text { Woodcock, Beamish e Makino } \\
\text { (1994) }\end{array}$ & 321 & Japão & Canadá; EUA & $\mathrm{FE}$ \\
\hline 60 & Chan (1995) & 100 & EUA & NI & NP \\
\hline 61 & Li (1995) & 1.235 & Japão + NI & EUA & $\mathrm{FE}$ \\
\hline 62 & Luo e Chen (1995) & 108 & NI & China & NP \\
\hline 63 & $\begin{array}{l}\text { Nitsch, Beamish e Makino } \\
\text { (1996) }\end{array}$ & 173 & Japão & Europa Ocidental & $\mathrm{FE}$ \\
\hline 64 & Benito (1997) & 153 & Noruega & $\mathrm{PD}+\mathrm{EE}$ & $\mathrm{NP}+\mathrm{FE}$ \\
\hline 65 & Leung (1997) & $116 / 98$ & EUA / NI & NI / EUA & NP \\
\hline 66 & Hennart, Kim e Zeng (1998) & 355 & Japão & EUA & NP \\
\hline 67 & Makino e Beamish (1998) & 917 & Japão & Ásia & NP \\
\hline 68 & Shaver (1998) & 213 & NI & EUA & $\mathrm{FE}$ \\
\hline 69 & H. Chen (1999) & 114 & Taiwan & $\begin{array}{l}\text { China; EUA; } \\
\text { Tailândia }\end{array}$ & NP \\
\hline 70 & Mata e Portugal (2000) & 1.033 & NI & Portugal & $\mathrm{NP}+\mathrm{FE}$ \\
\hline 71 & Vermeulen e Barkema (2001) & 1.349 & Holanda & NI & $\mathrm{FE}$ \\
\hline 26 & Brouthers (2002) & 83 & União Europeia & NI (27 países) & PM \\
\hline
\end{tabular}


Tabela 2 (continuação)

\begin{tabular}{llcccc}
\hline $\mathbf{N}^{\circ}$ & \multicolumn{1}{c}{ Artigo } & Amostra & $\begin{array}{c}\text { País/Região de } \\
\text { Origem }\end{array}$ & $\begin{array}{c}\text { País/Região de } \\
\text { Destino }\end{array}$ & $\begin{array}{c}\text { Modo de } \\
\text { Entrada } \\
\text { Estudado }\end{array}$ \\
\hline 72 & H. Chen e Hu (2002) & 470 & NI & China & PM \\
73 & Zhao e Luo (2002) & 319 & $\begin{array}{c}\text { Cingapura; EUA; Hong } \\
\text { Kong; Japão; Taiwan }\end{array}$ & China & NP \\
32 & $\begin{array}{l}\text { Brouthers, Brouthers e Werner } \\
\text { (2003) }\end{array}$ & 158 & $\begin{array}{c}\text { Alemanha; Holanda; } \\
\text { Reino Unido }\end{array}$ & $\begin{array}{c}\text { Europa Central e } \\
\text { Oriental }\end{array}$ & PM \\
74 & Pangarkar e Lim (2003) & 128 & Cingapura & PD + EE (18 países) & NP \\
75 & Delios e Beamish (2004) & 27.974 & Japão & PD + EE (135 países) & NP \\
76 & Gaur e Lu (2007) & 20.177 & Japão & PD + EE (> 100 & NP \\
77 & Kaya e Erden (2007) & 94 & Turquia & PD + EE (28 países) & NP \\
42 & $\begin{array}{l}\text { Brouthers, Brouthers e Werner } \\
\text { (2008) }\end{array}$ & 167 & $\begin{array}{c}\text { Alemanha; EUA; } \\
\text { Grécia; Holanda }\end{array}$ & Europa Central e & PM \\
78 & Gao, Pan, Lu e Tao (2008) & 245 & EUA & China & NP \\
79 & Jung, Beamish e Goerzen (2008) & 13.918 & EUA; Japão & NI & NP \\
80 & Kim e Gray (2008) & 222 & NI & Coreia do Sul & PM \\
81 & Slangen e Hennart (2008b) & 198 & Holanda & PD + EE & FE \\
82 & Georgopoulos e Preusse (2009) & 179 & EUA; Europa & Grécia & FE \\
& & Ocidental; Japão & & \\
\hline
\end{tabular}

Nota. (a) As células sombreadas referem-se a estudos de EMNs oriundas de economias emergentes. (b) A numeração dos artigos é considerada como uma continuação da Tabela 1.

Legendas: NI = não identificado; $\mathrm{PD}=$ países desenvolvidos; $\mathrm{EE}=$ economias emergentes; $\mathrm{NP}=$ nível de propriedade (subsidiária própria $v$ s joint venture) $\mathrm{FE}=$ forma de estabelecimento (investimento greenfield ou aquisição); $\mathrm{PM}=$ comparado com previsões do modelo teórico adotado no estudo específico.

\section{Resultados}

Os resultados foram divididos em cinco temas. Os três primeiros temas cobrem os antecedentes da escolha do nível de propriedade (subsidiária integral versus joint venture) e da forma de estabelecimento (investimento greenfield ou aquisição), além da escolha do tipo de atividade (produção versus distribuição). O quarto tema traz uma comparação dos modos de entrada escolhidos por EMNs originárias de diferentes países. Finalmente, o quinto tema trata do impacto da escolha de determinado modo de entrada sobre o desempenho da subsidiária internacional.

\section{Antecedentes da escolha do nível de propriedade (subsidiária integral versus joint venture)}

Os 41 estudos empíricos que tratam da escolha do nível de propriedade relacionam este nível (subsidiária de controle integral, designada pela sigla em inglês WOS, ou joint venture, designada por $\mathrm{JV})$, com dois grandes grupos de fatores: (a) fatores internos à empresa, tanto relativos à matriz quanto à subsidiária; e (b) fatores externos à empresa, que agregam tanto características da indústria onde a EMN atua quanto aspectos mercadológicos e institucionais do país hospedeiro.

A Tabela 3 apresenta um total de 40 fatores internos à empresa que aparecem nos estudos como antecedentes da escolha do nível de propriedade, ou seja, a escolha entre subsidiária de controle integral 
(WOS) e joint venture (JV). Verifica-se, entretanto, que apenas algumas poucas variáveis foram utilizadas com frequência em vários estudos, destacando-se cinco delas: (a) experiência internacional (22 estudos); (b) experiência no país hospedeiro (21 estudos); (c) intensidade tecnológica (26 estudos); (d) tamanho da empresa (27 estudos); e (e) tamanho relativo da subsidiária (17 estudos). Cabe ressaltar ainda que a forma de estabelecimento (aquisição versus investimento greenfield) foi também utilizada como antecedente em 10 dos 41 estudos, mas em oito deles não se obteve relação significativa.

Tabela 3

Antecedentes da Escolha do Nível de Propriedade (WOS versus JV) - Fatores Internos à Empresa

\begin{tabular}{|c|c|c|c|c|}
\hline \multirow[t]{2}{*}{ FATORES INTERNOS À EMPRESA } & \multicolumn{3}{|c|}{$\begin{array}{l}\text { Relação com Escolha do Nível de } \\
\text { Propriedade (WOS versus JV) }\end{array}$} & \multirow{2}{*}{$\begin{array}{c}\text { Total de } \\
\text { Estudos } \\
\text { com a } \\
\text { Variável }\end{array}$} \\
\hline & $\begin{array}{c}\text { Aumenta a } \\
\text { probabilidade } \\
\text { de WOS }\end{array}$ & $\begin{array}{c}\text { Aumenta a } \\
\text { probabilidade } \\
\text { de JV }\end{array}$ & $\begin{array}{c}\text { Não } \\
\text { significativa }\end{array}$ & \\
\hline Acompanhamento da dinâmica do mercado & & & 1 & 1 \\
\hline Capacidade de aprendizagem dinâmica & 1 & 1 & & 2 \\
\hline Capacidade de conexão da empresa & 1 & & & 1 \\
\hline Comunalidade & & & 1 & 1 \\
\hline Especificidade dos ativos & 4 & & 5 & 6 \\
\hline Estratégia internacional & 2 & 1 & 2 & 5 \\
\hline Experiência com IDE & & & 1 & 1 \\
\hline Experiência com JV & & 2 & & 2 \\
\hline Experiência com WOS & 4 & & 1 & 5 \\
\hline Experiência antiga com nível de propriedade & 1 & & & 1 \\
\hline Experiência recente com nível de propriedade & 1 & & & 1 \\
\hline Experiência em mercados semelhantes & 2 & & & 2 \\
\hline Experiência de transferência de know-how & & 1 & & 1 \\
\hline Experiência internacional & 7 & 1 & 14 & 22 \\
\hline Experiência na indústria & 1 & 1 & 1 & 3 \\
\hline Experiência no país hospedeiro & 10 & 4 & 7 & 21 \\
\hline Forma de estabelecimento & 2 & & 8 & 10 \\
\hline Grau de diversificação da empresa & & 1 & 2 & 3 \\
\hline Grau de diversificação dos produtos & 1 & 5 & 3 & 9 \\
\hline Grau de internacionalização da empresa & 1 & & & 1 \\
\hline Idade da subsidiária & 1 & & 3 & 4 \\
\hline IDE para acompanhamento de clientes & 1 & & 1 & 2 \\
\hline IDE para busca de ativos & 1 & 1 & & 2 \\
\hline IDE para expansão de mercados & 1 & 1 & & 2 \\
\hline
\end{tabular}


Tabela 3 (continuação)

\begin{tabular}{|c|c|c|c|c|}
\hline \multirow[t]{2}{*}{ FATORES INTERNOS À EMPRESA } & \multicolumn{3}{|c|}{$\begin{array}{l}\text { Relação com Escolha do Nível de } \\
\text { Propriedade (WOS versus JV) }\end{array}$} & \multirow{2}{*}{$\begin{array}{l}\text { Total de } \\
\text { Estudos } \\
\text { com a } \\
\text { Variável }\end{array}$} \\
\hline & $\begin{array}{c}\text { Aumenta a } \\
\text { probabilidade } \\
\text { de WOS }\end{array}$ & $\begin{array}{c}\text { Aumenta a } \\
\text { probabilidade } \\
\text { de JV }\end{array}$ & $\begin{array}{c}\text { Não } \\
\text { significativa }\end{array}$ & \\
\hline Intensidade de capital da empresa & 1 & & & 1 \\
\hline Intensidade de exportação da empresa & 3 & & 2 & 5 \\
\hline Intensidade publicitária da empresa & 3 & 3 & 5 & 11 \\
\hline Intensidade tecnológica da empresa & 12 & 4 & 10 & 26 \\
\hline Momento de entrada & 2 & & 5 & 7 \\
\hline Potencial de sinergias globais & 1 & & & 1 \\
\hline Relacionamento dos produtos & 1 & & 6 & 7 \\
\hline Reputação da empresa & 1 & & 1 & 2 \\
\hline Subsidiária como base exportadora & 1 & & 1 & 2 \\
\hline Tamanho da empresa & 10 & 5 & 12 & 27 \\
\hline Tamanho relativo da subsidiária & 2 & 6 & 9 & 17 \\
\hline Tipo de atividade da subsidiária & 2 & 1 & & 3 \\
\hline Tipo de indústria & 1 & 1 & 6 & 8 \\
\hline Vantagens de comercialização & & & 1 & 1 \\
\hline Vantagens de manufatura & 1 & & & 1 \\
\hline Vantagens de produtos & & & 1 & 1 \\
\hline
\end{tabular}

Nota. WOS = subsidiária integral; JV = joint venture.

Cabe chamar a atenção para o fato de que cada estudo revisado apresenta sua operacionalização das variáveis pesquisadas. Embora alguns autores utilizem operacionalizações similares, outros escolhem formas distintas de operacionalizar as variáveis, muitas vezes, em função do tipo de dados a que têm acesso. É possível, inclusive, que algumas diferenças de resultados se devam a diferentes formas de operacionalização das variáveis. No entanto, devido a limitações de espaço, não foi possível apresentar aqui essas diversas operacionalizações.

Outra observação que ressalta do exame dos resultados apresentados na Tabela 3 é a grande frequência de resultados não significativos. Aliás, verifica-se que as variáveis que apresentaram resultados não significativos foram geralmente aquelas bem pouco usadas. De qualquer modo, o panorama que emerge dos resultados obtidos com relação aos antecedentes da escolha do nível de propriedade em investimentos diretos no exterior sugere que esses indicadores assinalam resultados frequentemente contraditórios.

Na mesma linha, a Tabela 4 mostra os fatores externos à empresa que foram utilizados nos 41 estudos empíricos que abordaram os antecedentes do nível de propriedade (subsidiária integral versus joint venture). O mesmo panorama desenha-se tanto no que se refere à diversidade de fatores antecedentes (29 fatores) como aos resultados contraditórios obtidos nos testes empíricos. Igualmente, diferentes pesquisadores adotam, por vezes, operacionalizações distintas para as mesmas variáveis. Observa-se ainda que apenas três variáveis foram utilizadas com bastante frequência pelos pesquisadores: (a) distância cultural (25 estudos); (b) restrições ao investimento (17 estudos); e (c) riscopaís (17 estudos). 
Tabela 4

Antecedentes da Escolha do Nível de Propriedade (WOS versus JV) - Fatores Externos à Empresa

\begin{tabular}{|c|c|c|c|c|}
\hline \multirow[t]{2}{*}{ FATORES EXTERNOS À EMPRESA } & \multicolumn{3}{|c|}{$\begin{array}{l}\text { Relação com Escolha do Nível de } \\
\text { Propriedade (WOS versus JV) }\end{array}$} & \multirow{2}{*}{$\begin{array}{c}\text { Total de } \\
\text { Estudos } \\
\text { com a } \\
\text { Variável }\end{array}$} \\
\hline & $\begin{array}{c}\text { Aumenta a } \\
\text { probabilidade } \\
\text { de WOS }\end{array}$ & $\begin{array}{c}\text { Aumenta a } \\
\text { probabilidade } \\
\text { de JV }\end{array}$ & $\begin{array}{c}\text { Não } \\
\text { significativa }\end{array}$ & \\
\hline Avanço institucional & & 1 & & 1 \\
\hline Disseminação da corrupção & & 1 & & 1 \\
\hline Distância cultural & 5 & 13 & 7 & 25 \\
\hline Distância das normas sociais & & 1 & & 1 \\
\hline Distância educacional & & 1 & & 1 \\
\hline Distância institucional & & 2 & & 2 \\
\hline Distância legal & & & 1 & 1 \\
\hline Distância linguística & & 1 & 1 & 2 \\
\hline Distância no desenvolvimento econômico & & 2 & & 2 \\
\hline Grau de concentração industrial & 1 & & 3 & 4 \\
\hline Heterogeneidade do mercado & & & 1 & 1 \\
\hline Incerteza da demanda & & & 2 & 2 \\
\hline Incerteza econômica e política & & & 1 & 1 \\
\hline Incerteza ética e arbitrariedade & & 1 & & 1 \\
\hline Infraestrutura de conhecimento & 1 & & & 1 \\
\hline Intensidade de recursos naturais da indústria & 2 & 7 & & 9 \\
\hline Intensidade publicitária da indústria & & & 2 & 2 \\
\hline Intensidade tecnológica da indústria & 1 & 1 & 1 & 3 \\
\hline Nível de competição da indústria & 2 & & 3 & 5 \\
\hline Nível de desenvolvimento econômico & & 1 & 1 & 2 \\
\hline Nível tecnológico da indústria & 1 & & 1 & 1 \\
\hline Potencial de mercado & 1 & 1 & 2 & 4 \\
\hline Regulamentações governamentais & 2 & 3 & & 5 \\
\hline Restrições ao investimento & 2 & 11 & 4 & 27 \\
\hline Risco-país & 6 & 8 & 3 & 17 \\
\hline Tamanho do mercado & 1 & 1 & & 2 \\
\hline Taxa de crescimento do mercado & 1 & 4 & 4 & 9 \\
\hline Valor da marca da indústria & 1 & & & 1 \\
\hline Vantagens comparativas de custo & 1 & & 1 & 2 \\
\hline
\end{tabular}

Nota. WOS = subsidiária integral; JV = joint venture .

Assim, pode-se afirmar que, de forma geral, os estudos empíricos analisados não permitem extrair conclusões seguras sobre os antecedentes da decisão de escolha do nível de propriedade (subsidiária integral versus joint venture), tendo em vista a discrepância nos resultados obtidos (ora com maior 
probabilidade de WOS, ora com maior probabilidade de JV e, por vezes, mostrando resultados estatisticamente não significativos).

\section{Antecedentes da escolha da forma de estabelecimento}

O segundo aspecto analisado nos estudos empíricos selecionados refere-se aos antecedentes da escolha da forma de estabelecimento quando a empresa opta por investimento direto no exterior: aquisição de uma empresa já existente (aquisição) ou criação de nova empresa ( greenfield). Um total de 17 estudos analisados cobriu essa decisão.

Apresenta-se, a seguir, o panorama dos estudos empíricos que tratam da escolha da forma de estabelecimento. De forma similar à adotada anteriormente, as principais variáveis e construtos e os resultados obtidos também estão destacados em dois grandes grupos: (a) fatores internos à empresa, tanto relativos à matriz quanto à subsidiária; e (b) fatores externos à empresa, que agregam tanto características da indústria onde a EMN atua quanto aspectos mercadológicos e institucionais do país hospedeiro.

Em relação aos fatores internos à empresa (um total de 25 fatores identificados) que influenciam a escolha entre aquisição e greenfield (Tabela 5), vários dos 17 estudos empíricos utilizaram um conjunto de cinco variáveis como antecedentes da forma de estabelecimento. São elas: (a) intensidade tecnológica (12 estudos); (b) experiência internacional (11 estudos); (c) experiência no país de destino (9 estudos); (d) tamanho da empresa (9 estudos); e (e) tamanho relativo da subsidiária (9 estudos). Observa-se que estas variáveis são as mesmas que foram utilizadas com mais frequência nos estudos relativos ao nível de propriedade. Além disso, cabe salientar que a variável nível de propriedade foi utilizada como antecedente da forma de estabelecimento em seis estudos, sendo que, em quatro deles, os resultados mostraram-se estatisticamente significativos. Este resultado reforça a tese de que a escolha do nível de propriedade antecede a escolha da forma de estabelecimento, conforme postulado por RuizMoreno et al. (2007).

Tabela 5

Antecedentes da Escolha da Forma de Estabelecimento (Aquisição Versus Greenfield) - Fatores Internos à Empresa

\begin{tabular}{lcccc}
\hline FATORES INTERNOS À EMPRESA & \multicolumn{2}{c}{$\begin{array}{c}\text { Relação com Escolha da Forma de } \\
\text { Estabelecimento (Aquisição vs Greenfield) }\end{array}$} & $\begin{array}{c}\text { Total de } \\
\text { Estudos } \\
\text { com a } \\
\text { Variável }\end{array}$ \\
\cline { 2 - 4 } & $\begin{array}{c}\text { Aumenta a } \\
\text { probabilidade } \\
\text { de aquisição }\end{array}$ & $\begin{array}{c}\text { Aumenta a } \\
\text { probabilidade } \\
\text { de greenfield }\end{array}$ & $\begin{array}{c}\text { Não } \\
\text { significativa }\end{array}$ & \\
\hline Alavancagem financeira & & & 1 & 1 \\
Conhecimento tecnológico a ser transferido & & 2 & & 2 \\
Dependência de insumos da subsidiária & 1 & 1 & & 1 \\
Dotação de recursos humanos & 2 & & 1 & 2 \\
Estratégia internacional & 4 & 2 & 4 & 3 \\
Experiência com aquisições & & 2 & 4 & 9 \\
Experiência com greenfield & 5 & & 11 \\
Experiência internacional & 5 & & \\
Experiência no país de destino & & & \\
\hline
\end{tabular}


Tabela 5 (continuação)

\begin{tabular}{|c|c|c|c|c|}
\hline \multirow[t]{2}{*}{ FATORES INTERNOS À EMPRESA } & \multicolumn{3}{|c|}{$\begin{array}{l}\text { Relação com Escolha da Forma de } \\
\text { Estabelecimento (Aquisição vs Greenfield) }\end{array}$} & \multirow{2}{*}{$\begin{array}{c}\text { Total de } \\
\text { Estudos } \\
\text { com a } \\
\text { Variável }\end{array}$} \\
\hline & $\begin{array}{c}\text { Aumenta a } \\
\text { probabilidade } \\
\text { de aquisição }\end{array}$ & $\begin{array}{c}\text { Aumenta a } \\
\text { probabilidade } \\
\text { de greenfield }\end{array}$ & $\begin{array}{c}\text { Não } \\
\text { significativa }\end{array}$ & \\
\hline Flexibilidade baseada em aquisições & 1 & & & 1 \\
\hline Força de vendas da empresa & 1 & & & 1 \\
\hline Grau de autonomia da subsidiária & 2 & & & 2 \\
\hline Grau de diversificação da empresa & 5 & & 2 & 7 \\
\hline Grau de diversificação de produtos & 2 & 1 & 5 & 8 \\
\hline Intensidade publicitária da empresa & & 2 & 3 & 5 \\
\hline Intensidade tecnológica da empresa & & 8 & 4 & 12 \\
\hline Lucratividade da empresa & 1 & & & 1 \\
\hline Momento da entrada & 5 & & 2 & 7 \\
\hline Nível de propriedade & 2 & 2 & 2 & 6 \\
\hline Participação de mercado da empresa & & & 2 & 2 \\
\hline Relacionamento dos produtos & 2 & 3 & 3 & 8 \\
\hline Tamanho da empresa & 1 & 1 & 7 & 9 \\
\hline Tamanho relativo da subsidiária & 7 & & 2 & 9 \\
\hline Tipo de atividade da subsidiária & & 1 & & 1 \\
\hline Tipo de indústria & & & 3 & 3 \\
\hline
\end{tabular}

Em relação aos fatores externos à empresa, verifica-se, na Tabela 6, que apenas duas variáveis aparecem com maior frequência nos 17 estudos empíricos que tratam da escolha entre aquisição e greenfield: (a) taxa de crescimento de mercado (11 estudos); (b) distância cultural (ou seja, as diferenças culturais entre o país de origem e o país de destino do investimento) (10 estudos). Observa-se que as duas variáveis mais utilizadas na análise do nível de propriedade (restrições ao investimento e riscopaís) não tiveram a mesma relevância para a escolha da forma de estabelecimento.

Apesar de também se observar certa instabilidade dos resultados, pode-se verificar, nas Tabelas 5 e 6, que, não se considerando os resultados estatisticamente não significativos, há uma tendência a que os resultados dos testes apresentem maior consistência, com diferentes variáveis favorecendo uma ou outra forma de estabelecimento. 
Tabela 6

Antecedentes da Escolha da Forma de Estabelecimento (Aquisição Versus Greenfield) - Fatores Externos à Empresa

\begin{tabular}{|c|c|c|c|c|}
\hline \multirow[t]{2}{*}{ FATORES EXTERNOS À EMPRESA } & \multicolumn{3}{|c|}{$\begin{array}{l}\text { Relação com Escolha da Forma de } \\
\text { Estabelecimento (Aquisição vs Greenfield) }\end{array}$} & \multirow{2}{*}{$\begin{array}{l}\text { Total de } \\
\text { Estudos } \\
\text { com a } \\
\text { Variável }\end{array}$} \\
\hline & $\begin{array}{c}\text { Aumenta a } \\
\text { probabilidade } \\
\text { de aquisição }\end{array}$ & $\begin{array}{c}\text { Aumenta a } \\
\text { probabilidade } \\
\text { de greenfield }\end{array}$ & $\begin{array}{c}\text { Não } \\
\text { significativa }\end{array}$ & \\
\hline Avanço institucional & 1 & & & 1 \\
\hline Aversão à incerteza no país hospedeiro & & 1 & & 1 \\
\hline Distância cultural & & 6 & 4 & 10 \\
\hline Falta de alvos para aquisição & & 2 & & 2 \\
\hline Grau de concentração industrial & & 1 & 4 & 5 \\
\hline Incentivos ao investimento & & & 2 & 2 \\
\hline Incerteza ambiental & & 1 & & 1 \\
\hline Incerteza da demanda & & 1 & & 1 \\
\hline Intensidade de recursos naturais da indústria & & 1 & & 1 \\
\hline Intensidade publicitária da indústria & 2 & & & 2 \\
\hline Intensidade tecnológica da indústria & & & 1 & 1 \\
\hline Intensidade tecnológica do país hospedeiro & 1 & & & 1 \\
\hline Nível de desenvolvimento econômico & 5 & & 1 & 6 \\
\hline Nível tecnológico da indústria & & & 1 & 1 \\
\hline Potencial de mercado & 1 & & & 1 \\
\hline Qualidade dos insumos & 1 & & & 1 \\
\hline Regulamentações governamentais & & & 1 & 1 \\
\hline Restrições ao investimento & 1 & 1 & 3 & 5 \\
\hline Risco-país & & 2 & & 2 \\
\hline Tamanho do mercado & & & 3 & 3 \\
\hline Taxa de crescimento do mercado & 3 & 5 & 3 & 11 \\
\hline Tipo de cliente & 1 & & & 1 \\
\hline Valor da marca da indústria & & & 1 & 1 \\
\hline Valor relativo ao preço das ações & & & 1 & 1 \\
\hline Vantagens comparativas de custo & & & 1 & 1 \\
\hline
\end{tabular}

\section{Escolha do tipo de atividade}

A escolha do tipo de atividade a ser exercida pela EMN, quando de sua entrada no mercado externo (distribuição ou produção), é uma decisão prática tão importante quanto aquelas que envolvem o nível de propriedade e a forma de estabelecimento. Entretanto os determinantes desta escolha não foram adequadamente abordados pela literatura (Buckley \& Casson, 1998; Kleinert \& Toubal, 2010). Foram identificados apenas dois estudos empíricos na literatura de modos de entrada que tratam o tipo de atividade como variável dependente (Delios \& Henisz, 2003a; Pla-Barber, 2001). Nas demais 
pesquisas revisadas, o tipo de atividade foi utilizado apenas como variável independente (Brouthers, Brouthers, \& Nakos, 1998; Delios \& Henisz, 2003b) ou como variável de controle (Bell, 1996; Dikova \& Witteloostuijn, 2007; Yiu \& Makino, 2002).

Delios e Henisz (2003a), a partir de uma amostra de 6.465 subsidiárias internacionais de 665 EMNs industriais japonesas em 49 países, analisaram três tipos de atividade: (a) distribuição; (b) planta de manufatura com JV; e (c) planta de manufatura com WOS. Os resultados mostram que quanto maior a incerteza política, maior a probabilidade de entrada com subsidiária de distribuição.

Pla-Barber (2001), por sua vez, utilizou um modelo logit aplicado a uma amostra de 323 empresas espanholas com atividades internacionais para analisar o impacto de diversos fatores sobre a internalização das atividades de distribuição e de produção no exterior. Os resultados mostraram que a intangibilidade e a natureza tácita dos produtos e processos envolvidos no IDE encontravam-se associados às subsidiárias de vendas e produção de controle integral.

\section{Modos de entrada adotados por empresas segundo o país ou região de origem}

Buscou-se ainda comparar os modos de entrada adotados pelas EMNs de países desenvolvidos com aqueles das EMNs de economias emergentes. Para a realização desta análise, somou-se o total de casos relativos a cada modo de entrada segundo o nível de propriedade (Tabela 7) e a forma de estabelecimento (Tabela 8). Graças ao razoável número de estudos tendo EUA, Japão e Europa Ocidental como origem das EMNs, estes países e regiões estão apresentados de forma discriminada. Já em relação às empresas oriundas de economias emergentes, devido ao número reduzido de estudos identificados durante a revisão e, ainda, pelo fato de nenhum país de origem ter sido estudado de maneira preponderante, os dados relativos a este grupo de países estão apresentados de forma consolidada. Mesmo assim, os estudos de economias emergentes retratam predominantemente países asiáticos (a única exceção é a Turquia), o que dá certa homogeneidade ao agrupamento.

Cabe observar que o Japão é o país mais estudado nos estudos revisados. Isso se deve a dois fatores. O primeiro é o fato de que a multinacionalização das empresas japonesas ocorre de forma massiva a partir da segunda metade da década de 1980, sendo, portanto, um fenômeno recente e que atraiu a atenção dos pesquisadores da área de negócios internacionais, enquanto a de empresas americanas e europeias tem início na virada do século XIX para o século XX e estende-se por todo o século XX. Assim, o fato de a multinacionalização das empresas japonesas ter ocorrido em um período recente e relativamente em curto de tempo permite trabalhar com amostras mais homogêneas. $O$ segundo fator é a maior disponibilidade de dados secundários sobre essas empresas.

Especificamente com relação aos números de subsidiárias, conforme a Tabela 7, o leitor deve ser advertido de que uma mesma subsidiária pode ter sido utilizada em vários estudos, portanto, introduzindo um problema de recontagem da mesma unidade organizacional. Não obstante, os resultados da Tabela 7 servem para indicar possíveis diferenças de escolha em função do país de origem, conquanto devam ser considerados com cautela. 
Tabela 7

Escolha do Nível de Propriedade Segundo a Origem das EMNs

\begin{tabular}{lcc}
\hline PAÍSES/REGIÕES DE ORIGEM DOS & \multicolumn{2}{c}{ Número de Subsidiárias segundo o Nível de Propriedade } \\
\cline { 2 - 3 } INVESTIMENTOS & JV & WOS \\
\hline EUA & 2.925 & 13.650 \\
Europa Ocidental & 1.901 & 2.233 \\
Japão & 32.422 & 31.705 \\
Outros Países Desenvolvidos & 575 & 420 \\
Total de Países Desenvolvidos & $\mathbf{3 7 . 8 2 3}$ & $\mathbf{4 8 . 0 0 8}$ \\
Total de Economias Emergentes & $\mathbf{1 . 1 2 3}$ & $\mathbf{1 . 0 2 9}$ \\
\hline
\end{tabular}

Tendo em mente as ressalvas anteriores com relação ao nível de propriedade, parece haver diferenças importantes entre as EMNs de países desenvolvidos e de economias emergentes. Em termos consolidados, há indicações de que as EMNs de economias emergentes parecem utilizar as JVs como modo de entrada preferencial, enquanto suas concorrentes de países desenvolvidos indicam preferência por WOSs.

Entretanto, quando os dados dos países desenvolvidos são analisados separadamente, há indicações de que as EMNs japonesas utilizam mais as JVs, o que não parece ocorrer entre as multinacionais europeias e, principalmente, norte-americanas, que revelam preferência por WOSs. É possível que a aparente maior utilização de JVs pelas empresas japonesas se deva ao interesse na aquisição de conhecimento tácito, seja de natureza tecnológica ou mercadológica. Já as EMNs norteamericanas e europeias, por serem mais antigas, talvez, prefiram utilizar WOSs em seu processo de expansão internacional a fim de evitar a disseminação de seu know-how devido a comportamentos oportunistas de eventuais parceiros.

As observações anteriores estão em consonância com Jung, Beamish e Goerzen (2008), que realizaram estudo comparando as estratégias de propriedade utilizadas pelas EMNs japonesas e norteamericanas. Segundo os autores, os resultados encontrados fornecem forte apoio para a afirmação de que o país de origem tem um efeito evidente sobre a estratégia de propriedade utilizada pelas EMNs em seus investimentos diretos no exterior.

Tabela 8

Escolha da Forma de Estabelecimento Segundo a Origem das EMNs

\begin{tabular}{lcc}
\hline PAÍ́SES/REGIÕES DE ORIGEM DOS & \multicolumn{2}{c}{ Número de Subsidiárias segundo a Forma de Estabelecimento } \\
\cline { 2 - 3 } INVESTIMENTOS & Greenfield & Aquisição \\
\hline EUA & - & - \\
Europa Ocidental & 1.999 & 4.162 \\
Japão & 1.900 & 701 \\
Outros Países Desenvolvidos & 1.866 & 3.830 \\
Total de Países Desenvolvidos & $\mathbf{5 . 7 6 5}$ & $\mathbf{8 . 6 9 3}$ \\
Total de Economias Emergentes & $\mathbf{2 7 5}$ & $\mathbf{3 7 8}$ \\
\hline
\end{tabular}

Já em relação à forma de estabelecimento, os modos de entrada adotados pelas EMNs de países desenvolvidos e de economias emergentes não apresentam divergência quando analisados de forma 
consolidada, pois as empresas de ambas as regiões parecem utilizar aquisições de maneira preferencial. Cabe ressaltar que não foram encontrados estudos relativos às formas de estabelecimento adotadas pelas EMNs norte-americanas. Possivelmente, tais estudos foram realizados em anos anteriores a 1990, visto que a expansão internacional dessas empresas teve início na passagem do século XIX para o século XX (Ietto-Gillies, 2005).

Entretanto, tal como observado com relação ao nível de propriedade, há indicações de que exista diferença no padrão adotado pelas EMNs de países desenvolvidos. Enquanto as EMNs europeias parecem mostrar preferência por aquisições, já suas congêneres japonesas indicam a adoção de mais investimentos greenfield. Talvez, a grande distância cultural entre o Japão e o Ocidente tenha motivado as EMNs japonesas a evitar aquisições devido à dificuldade de integrar empresas com culturas próprias previamente estabelecidas. Já para as empresas europeias, este problema se apresenta com menor intensidade, uma vez que sua expansão internacional foi iniciada dentro da própria Europa. Estes resultados estão em consonância com Hennart e Park (1993), que observaram que 63,4\% das EMNs japonesas estudadas utilizaram investimentos greenfield, e com Larimo (2003), que constatou que as EMNs de todos os países escandinavos têm acentuada preferência por aquisições: $74,3 \%$ para Dinamarca, 70,4\% para Finlândia, 71,8\% para Noruega e 74,7\% para Suécia.

\section{Decisões de escolha de modos de entrada de IDE e desempenho da subsidiária internacional}

Foram identificados 25 estudos empíricos que, dentro dos critérios estabelecidos, analisavam a relação entre a adoção de modos de entrada em termos de nível de propriedade (WOS ou JV) ou forma de estabelecimento (aquisição vs greenfield) e o desempenho da subsidiária internacional. Desses, 17 estudos avaliaram de alguma forma a relação entre nível de propriedade e desempenho da subsidiária internacional (Tabela 9); e 11 estudos, a relação entre forma de estabelecimento e desempenho da subsidiária internacional. Observe-se que os indicadores apresentados na Tabela 9 são diferentes medidas operacionais do construto desempenho da subsidiária internacional. A grande variedade de medidas utilizada pelos diversos pesquisadores é um elemento que, reconhecidamente, dificulta a comparação dos resultados obtidos pelos estudos.

Tabela 9

Relação Entre Nível de Propriedade e Desempenho da Subsidiária

\begin{tabular}{|c|c|c|c|c|}
\hline \multirow[t]{2}{*}{ INDICADOR DE DESEMPENHO } & \multicolumn{3}{|c|}{$\begin{array}{l}\text { Relação com Escolha do Nível de Propriedade } \\
\text { (WOS } v s \text { JV) }\end{array}$} & \multirow{2}{*}{$\begin{array}{c}\text { Total de } \\
\text { Estudos } \\
\text { com a } \\
\text { Variável }\end{array}$} \\
\hline & $\begin{array}{c}\text { Maior a } \\
\text { probabilidade } \\
\text { de sucesso de } \\
\text { WOS }\end{array}$ & $\begin{array}{c}\text { Maior a } \\
\text { probabilidade } \\
\text { de sucesso de } \\
\text { JV }\end{array}$ & $\begin{array}{c}\text { Não } \\
\text { significativa }\end{array}$ & \\
\hline Cobertura de taxa de juros & & & 1 & 1 \\
\hline Coeficiente de endividamento & & 1 & & 1 \\
\hline Crescimento das exportações & 1 & & & 1 \\
\hline Crescimento das receitas no exterior & & & 1 & 1 \\
\hline Crescimento das vendas & & & 2 & 2 \\
\hline Crescimento do lucro operacional & & & 1 & 1 \\
\hline Disponibilidade de caixa & & & 1 & 1 \\
\hline Giro de contas a receber & & & 1 & 1 \\
\hline
\end{tabular}


Tabela 9 (continuação)

\begin{tabular}{|c|c|c|c|c|}
\hline \multirow[t]{2}{*}{ INDICADOR DE DESEMPENHO } & \multicolumn{3}{|c|}{$\begin{array}{l}\text { Relação com Escolha do Nível de Propriedade } \\
\text { (WOS vs JV) }\end{array}$} & \multirow{2}{*}{$\begin{array}{c}\text { Total de } \\
\text { Estudos } \\
\text { com a } \\
\text { Variável }\end{array}$} \\
\hline & $\begin{array}{c}\text { Maior a } \\
\text { probabilidade } \\
\text { de sucesso de } \\
\text { WOS }\end{array}$ & $\begin{array}{c}\text { Maior a } \\
\text { probabilidade } \\
\text { de sucesso de } \\
\text { JV }\end{array}$ & $\begin{array}{c}\text { Não } \\
\text { significativa }\end{array}$ & \\
\hline Giro de estoques & & & 1 & 1 \\
\hline Giro dos ativos totais & 1 & & & 1 \\
\hline Liquidez corrente & 1 & & & 1 \\
\hline Longevidade & 2 & 1 & & 3 \\
\hline Lucratividade & 1 & 2 & & 3 \\
\hline Margem de lucro bruto & & & 1 & 1 \\
\hline Margem de lucro operacional & 1 & & & 1 \\
\hline Receitas no exterior/vendas totais & & & 1 & 1 \\
\hline Retorno sobre ativos antes dos impostos & & & 1 & 1 \\
\hline Retorno sobre ativos depois dos impostos & & & 1 & 1 \\
\hline Retorno sobre o investimento no exterior & & & 1 & 1 \\
\hline Retorno sobre vendas & & & 2 & 2 \\
\hline Satisfação & 1 & & 2 & 3 \\
\hline Sobrevivência & 2 & 1 & 3 & 6 \\
\hline
\end{tabular}

Nota. WOS = subsidiária integral; JV = joint venture.

Os resultados dos 17 estudos empíricos que avaliaram a relação entre o desempenho da subsidiária e o nível de propriedade adotado (WOS versus JV) não apresentaram tendência para nenhum dos dois tipos de entrada. Esta avaliação é válida tanto quando se observam medidas objetivas quanto medidas subjetivas. $\mathrm{O}$ indicador mais utilizado foi a sobrevivência da subsidiária. Verifica-se que os resultados deste indicador são contraditórios nos seis estudos analisados (ora com maior sucesso para WOS, ora para JV e, por vezes, não significativos). O mesmo acontece com as medidas subjetivas, entre as quais, satisfação com o desempenho e lucratividade foram os indicadores mais utilizados. Os resultados sugerem que o nível de propriedade não tem impacto apreciável sobre o desempenho da subsidiária, como apontado por diversos autores (p.ex., Bausch \& Krist, 2007; Reus \& Rottig, 2009).

Já no que se refere à relação entre forma de estabelecimento (aquisição versus greenfield) e desempenho, nos 11 estudos empíricos que analisaram essa relação, foram utilizados apenas quatro indicadores para medir o desempenho da subsidiária (Tabela 10). 
Tabela 10

Relação Entre Forma de Propriedade e Desempenho da Subsidiária

\begin{tabular}{lcccc}
\hline INDICADOR DE DESEMPENHO & \multicolumn{2}{c}{$\begin{array}{c}\text { Relação com Escolha da Forma de } \\
\text { Estabelecimento (Aquisição vs Greenfield) }\end{array}$} & $\begin{array}{c}\text { Total de } \\
\text { Estudos } \\
\text { com a } \\
\text { Variável }\end{array}$ \\
\cline { 2 - 4 } & $\begin{array}{c}\text { Maior a } \\
\text { probabilidade } \\
\text { de sucesso de } \\
\text { aquisição }\end{array}$ & $\begin{array}{c}\text { Maior a } \\
\text { probabilidade } \\
\text { de sucesso de } \\
\text { greenfield }\end{array}$ & $\begin{array}{c}\text { Não } \\
\text { significativa }\end{array}$ & \\
\hline Lucratividade & 1 & 1 & 1 & 2 \\
Retorno sobre o capital próprio & 1 & & 2 & 1 \\
Satisfação & 1 & 4 & 7 \\
\hline Sobrevivência & & & 1 \\
\hline
\end{tabular}

Percebe-se, novamente, que não há tendência em favor de nenhum dos dois tipos de entrada (aquisição versus investimento greenfield). Além disso, a grande maioria dos estudos utilizou a sobrevivência da subsidiária como indicador preferencial. Os resultados deste indicador, entretanto, também, mostram-se contraditórios nos sete estudos analisados (ora com maior sucesso para aquisição, ora para investimento greenfield e, por vezes, não significante). Assim, de forma semelhante aos estudos relativos ao nível de propriedade, os resultados sugerem que a forma de estabelecimento também não parece ter influência importante no desempenho da subsidiária internacional.

\section{Conclusões}

As evidências colhidas pela revisão da literatura sobre antecedentes da escolha de modo de entrada são surpreendentemente contraditórias e fragmentadas, pois as relações examinadas, dependendo do estudo, revelaram relações positivas, negativas, ou não foi encontrada nenhuma relação entre as variáveis consideradas. O caráter contraditório e fragmentado encontrado nos resultados dos estudos analisados pode ser atribuído a vários motivos, sobre os quais se especula a seguir.

O primeiro deles é o país de origem das empresas multinacionais. Quando se agrupam os resultados dos estudos sobre escolhas dos modos de entrada, por tipo de países ou regiões de origem das EMNs (p.ex., desenvolvidos versus emergentes, ocidentais desenvolvidos versus japoneses), parecem emergir diferenças significativas, sugerindo que o país ou região de origem das EMNs pode desempenhar papel relevante na explicação dos modos de entrada. Assim, é de se esperar que as decisões estratégicas de entrada das EMNs brasileiras não necessariamente sigam os padrões adotados pelas empresas de outras economias emergentes como China, Índia e Coreia do Sul, tendo em vista as diferenças políticas, econômicas, sociais, culturais e geográficas entre os países. Por exemplo, há evidências, no caso do Brasil, de que as empresas brasileiras apresentam forte preferência por controle majoritário ou integral de suas operações (Rocha, 2003), que a autora atribui a motivos de ordem cultural.

Uma segunda explicação para os resultados obtidos até agora por essa linha de pesquisa pode ser decorrente do país de destino dos investimentos da multinacional. Alguns países de destino dos investimentos de EMNs, pelo menos em determinados períodos e para determinadas indústrias, podem não permitir, ou não terem permitido, investimentos diretos sob a forma de subsidiárias integrais, admitindo unicamente joint ventures. Tal foi o caso da Índia, antes da liberalização econômica da década de 1990 (embora essa política ainda persista em algumas indústrias consideradas estratégicas), e da China, entre muitos outros países que poderiam ser citados. Assim, em determinadas situações, as EMNs 
seriam forçadas a optar por uma joint venture, mesmo se sua preferência fosse por uma subsidiária integral.

Uma terceira possibilidade pode decorrer das variáveis escolhidas e de sua forma de operacionalização. Observou-se, ao longo do trabalho, não só o uso de diferentes antecedentes da escolha do modo de entrada, como também o uso de diferentes indicadores para uma mesma variável. Portanto, é possível que diferenças nos resultados reflitam essas escolhas. Trata-se de um problema já apontado por autores de revisões sobre outros temas da área de negócios internacionais (Katsikeas, Leonidou, \& Morgan, 2000; Sousa, 2004).

Quando se trata da relação entre modo de entrada e desempenho, os resultados empíricos existentes na literatura levantada sugerem que o modo de entrada não é o único fator e, talvez, nem mesmo o fator preponderante a influenciar o desempenho da subsidiária. Ademais, os resultados obtidos nos estudos pertinentes à relação entre modo de entrada e desempenho da subsidiária internacional, também, parecem depender do tipo de medida e do indicador considerado.

São escassas as pesquisas relativas aos modos de entrada de EMNs oriundas de países emergentes, sendo a quase totalidade sobre países asiáticos e poucos estudos empíricos no tocante ao mesmo país. Em particular, não foi encontrado, na literatura levantada, estudo sobre a relação do modo de entrada e desempenho de subsidiárias internacionais de multinacionais brasileiras, apesar de ser o Brasil uma das principais economias emergentes. O motivo para tal deve-se, possivelmente, pelo fato de não existirem listas exaustivas da população de EMNs brasileiras e, muito menos, bancos de dados que tragam informações específicas de subsidiárias. Além disso, mesmo as EMNs brasileiras de capital aberto não publicam ou não dispõem de informações relativas a cada subsidiária, o que força a coleta por meio de questionários, com elevado custo para obtenção de dados e baixas taxas de resposta. De qualquer modo, a literatura existente não fornece subsídios para predizer os padrões dos modos de entrada adotados pelas EMNs brasileiras.

Especificamente, apresentam-se, a seguir, sugestões para aprimoramento das pesquisas sobre modos de entrada em mercados externos por empresas manufatureiras.

Primeiro, sugere-se que os pesquisadores adotem em seus estudos os antecedentes que aparecem com mais frequência na literatura internacional, assim como as medidas operacionais mais utilizadas, de modo a permitir maior comparabilidade dos estudos realizados em diferentes países e regiões do mundo.

Segundo, é possível que variáveis ainda não pesquisadas possam explicar melhor quais os antecedentes da decisão de escolha de modos de entrada em mercados externos. Para tal, recomenda-se a realização de estudos exploratórios, qualitativos, que busquem entender de que forma tais decisões são tomadas em empresas manufatureiras. Os estudos qualitativos, embora não permitam generalizações para a população, podem ser uma forma valiosa de gerar novas hipóteses a serem futuramente testadas.

Terceiro, é possível que o país de destino, mais do que o país de origem, impacte a decisão de modos de entrada para investimento direto. Estudos relativos aos modos de entrada escolhidos por EMNs originárias de diferentes países em um mesmo país de destino dos investimentos podem ser úteis ao entendimento do fenômeno.

Quarto, maior controle da ocasião em que foram tomadas as decisões de investimento direto em mercados externos pode proporcionar novos insights quanto ao fenômeno. Por exemplo, as joint ventures tornaram-se muito mais frequentes a partir da década de 1990 do que antes. Assim, é possível que subsidiárias implantadas mais recentemente mostrem maior presença de joint ventures do que aquelas estabelecidas há mais tempo.

Cabe observar, por derradeiro, que, nos últimos dois anos e meio, período não coberto pela avaliação dos estudos empíricos deste trabalho, verificou-se maior ênfase em estudos que abordam modos de entrada de multinacionais em mercados emergentes ou em transição, embora parte desses estudos tenha sido publicada em periódicos de menor impacto. Por exemplo, M.-Y. Chen (2012) mostra 
que as empresas taiwanesas preferem subsidiárias de propriedade integral em seus investimentos na China, sendo essa modalidade mais rentável do que as joint ventures. No entanto, quando se trata de empresas com pouca experiência, as joint ventures revelam-se mais rentáveis. Murray, Ju e Gao (2012) verificaram que empresas que entraram na China por meio de subsidiárias integrais não apresentaram diferenças significativas em termos de desempenho em relação a joint ventures, mas ambos os modos de entrada mostraram desempenho superior ao de alianças contratuais. Já o estudo realizado por Haar e Marinescu (2014), com multinacionais de vários países que investiram na Romênia, assinala preferência por investimentos greenfield em relação a aquisições, indicando ainda que as aquisições apresentaram melhor desempenho do que os investimentos greenfield.

Cabe salientar, também, dois trabalhos teóricos recentes de grande relevância relacionados a modos de entrada por investimento direto: os de Shaver (2013) e de Martin (2013), publicados no mesmo número do Journal of International Business Studies. Ambos tratam de questões críticas - teóricas e metodológicas - relativas à pesquisa sobre o tema. Shaver (2013) chama a atenção para o fato de que as pesquisas a respeito dos modos de entrada e desempenho não são relevantes apenas para a teoria, mas que têm forte impacto potencial sobre as empresas, por se tratar de uma decisão crítica associada a investimentos diretos no exterior. Assim, base empírica mais sólida e maior consistência metodológica nas pesquisas relativas a modos de entrada têm o potencial de contribuir para decisões empresariais mais eficazes.

A presente revisão de literatura sobre modos de entrada com capital próprio em mercados internacionais destaca algumas limitações que devem ser consideradas, além daquelas já apontadas no decorrer do artigo. Uma revisão da literatura está limitada àquilo que foi publicado sobre o tópico específico, nas revistas científicas que foram objeto da revisão e conforme o foco escolhido e do período analisado (no caso do presente estudo, de 1990 a 2011). Assim, não foram considerados, no presente trabalho, estudos sobre multinacionais brasileiras que não obedeciam estritamente aos critérios adotados. Há já uma vasta literatura no Brasil, sobre os mais diversos aspectos da internacionalização de empresas brasileiras, cobrindo uma variedade de outros aspectos das decisões de internacionalização que não aqueles abordados nesta revisão.

\section{Referências}

Agarwal, S. (1994). Socio-cultural distance and the choice of joint ventures: a contingency perspective. Journal of International Marketing, 2(2), 63-80.

Anand, J., \& Delios, A. (2002). Absolute and relative resources as determinants of international acquisitions. Strategic Management Journal, 23(2), 119-134. doi: 10.1002/smj.215

Andersson, T., \& Svensson, R. (1994). Entry modes for direct investment determined by the composition of firm-specific skills. Scandinavian Journal of Economics, 96(4), 551-560.

Barkema, H. G., \& Vermeulen, F. (1998). International expansion through start-up or acquisition: a learning perspective. Academy of Management Journal, 41(1), 7-26. doi: 10.2307/256894

Bausch, A., \& Krist, M. (2007). The effect of context-related moderators on the internationalizationperformance relationship: evidence from meta-analysis. Management International Review, 47(3), 319-347. doi: 10.1007/s11575-007-0019-z

Bell, J. H. J. (1996). Single or joint venturing? A comprehensive approach to foreign entry mode choice. Aldershot, England: Avebury.

Benito, G. R. G. (1996). Ownership structures of Norwegian foreign subsidiaries in manufacturing. International Trade Journal, 10(2), 157-198. doi: 10.1080/08853909608523852 
Benito, G. R. G. (1997). Divestment of foreign production operations. Applied Economics, 29(10), 13651377. doi: $10.1080 / 00036849700000027$

Brouthers, K. D. (2002). Institutional, cultural and transaction cost influences on entry mode choice and performance. Journal of International Business Studies, 33(2), 203-221. doi: 10.1057/palgrave.jibs.8491013

Brouthers, K. D., \& Brouthers, L. E. (2000). Acquisition or greenfield start-up? Institutional, cultural and transaction cost influences. Strategic Management Journal, 21(1), 89-97. doi: 10.1002/(SICI)1097-0266(200001)21:1<89::AID-SMJ85>3.0.CO;2-8

Brouthers, K. D., \& Brouthers, L. E. (2001). Explaining the national cultural distance paradox. Journal of International Business Studies, 32(1), 177-189. doi:10.1057/palgrave.jibs.8490944

Brouthers, K. D., Brouthers, L. E., \& Nakos, G. (1998). Entering Central and Eastern Europe: risks and cultural barriers. Thunderbird International Business Review, 40(5), 485-504.

Brouthers, K. D., Brouthers, L. E., \& Werner, S. (2003). Transaction cost-enhanced entry mode choices and firm performance. Strategic Management Journal, 24(12), 1239-1248. doi: 10.1002/smj.362

Brouthers, K. D., Brouthers, L. E., \& Werner, S. (2008). Resource-based advantages in an international context. Journal of Management, 34(2), 189-217. doi: 10.1177/0149206307312508

Brouthers, K. D., \& Dikova, D. (2010). Acquisitions and real options: the greenfield alternative. Journal of Management Studies, 47(6), 1048-1071. doi: 10.1111/j.1467-6486.2009.00875.x

Brouthers, K. D., \& Hennart, J. F. (2007). Boundaries of the firm: insights from international entry mode research. Journal of Management, 33(3), 395-425. doi: 10.1177/0149206307300817

Buckley, P. J., \& Casson, M. C. (1998). Analyzing foreign entry strategies: extending the internalization approach. Journal of International Business Studies, 29(3), 539-561. doi: 10.1057/palgrave.jibs. 8490006

Cavusgil, S. T., Knight, G., \& Riesenberger, J. R. (2010). Negócios internacionais: estratégia, gestão \& novas realidades. São Paulo: Pearson.

Chan, P. S. (1995) International joint ventures vs. wholly owned subsidiaries. Multinational Business Review, 3(1), 37-44.

Chen, H. (1999). International performance of multinationals: a hybrid model. Journal of World Business, 34(2), 157-170. doi: 10.1016/S1090-9516(99)00014-0

Chen, H., \& Hu, M. Y. (2002). An analysis of determinants of entry mode and its impact on performance. International Business Review, 11(2), 193-210. doi: 10.1016/S0969-5931(01)00055-5

Chen, M.-Y. (2012). Entry mode choice and performance: evidence from Taiwanese FDI in China. Emerging Markets Finance \& Trade, 48(3), 31-51. doi: 10.2753/REE1540-496X480302

Chen, S.-F. S., \& Hennart, J. F. (2002). Japanese investors' choice of joint ventures versus whollyowned subsidiaries in the US: the role of market barriers and firm capabilities. Journal of International Business Studies, 33(1), 1-18. doi: 10.1057/palgrave.jibs.8491002

Chen, S.-F. S., \& Zeng, M. (2004). Japanese investors' choice of acquisitions vs. startups in the US: The role of reputation barriers and advertising outlays. International Journal of Research in Marketing, 21(2), 123-136. doi: 10.1016/j.ijresmar.2003.06.002 
Chiao, Y.-C., Lo, F.-Y., \& Yu, C.-M. (2010). Choosing between wholly-owned subsidiaries and joint ventures of MNCs from an emerging market. International Marketing Review, 27(3), 338-365. doi: 10.1108/02651331011047998

Cho, K. R., \& Padmanabhan, P. (1995). Acquisition versus new venture: the choice of foreign establishment mode by Japanese firms. Journal of International Management, 1(3), 255-285.

Cho, K. R., \& Padmanabhan, P. (2001). The relative importance of old and new decision specific experience in foreign ownership strategies: an exploratory study. International Business Review, 10(6), 645-659. doi: 10.1016/S0969-5931(01)00036-1

Cho, K. R., \& Padmanabhan, P. (2005). Revisiting the role of cultural distance in MNC's foreign ownership mode choice: the moderating effect of experience attributes. International Business Review, 14(3), 307-324. doi: 10.1016/j.ibusrev.2005.01.001

Chowdhury, J. (1992). Performance of international joint ventures and wholly owned foreign subsidiaries: a comparative perspective. Management International Review, 32(2), 115-133.

Cleeve, E. (1997). The motives for joint ventures: a transaction cost analysis of Japanese MNEs in the UK. Scottish Journal of Political Economy, 44(1), 31-43. doi: 10.1111/1467-9485.00043

Cui, L., \& Jiang, F. (2009). FDI entry mode choice of Chinese firms: a strategic behavior perspective. Journal of World Business, 44(4), 434-444. doi: 10.1016/j.jwb.2008.11.004

Cui, L., Jiang, F., \& Stening, B. (2011). The entry-mode decision of Chinese outward FDI: firm resources, industry conditions, and institutional forces. Thunderbird International Business Review, 53(4), 483-499. doi: 10.1002/tie.20425

Delios, A., \& Beamish, P. W. (1999). Ownership strategy of Japanese firms: transactional, institutional, and experience influences. Strategic Management Journal, 20(10), 915-933. doi: 10.1002/(SICI)1097-0266(199910)20:10<915::AID-SMJ51>3.0.CO;2-0

Delios, A., \& Beamish, P. W. (2004). Joint venture performance revisited: Japanese foreign subsidiaries worldwide. Management International Review, 44(1), 69-91.

Delios, A., \& Henisz, W. J. (2003a). Policy uncertainty and the sequence of entry by Japanese firms, 1980-1998. Journal of International Business Studies, 34(3), 227-241. doi: 10.1057/palgrave.jibs. 8400031

Delios, A., \& Henisz, W. J. (2003b). Political hazards, experience, and sequential entry strategies: the international expansion of Japanese firms, 1980-1998. Strategic Management Journal, 24(11), 1153-1164. doi: $10.1002 / \mathrm{smj} .355$

Demirbag, M., McGuinness, M., \& Altay, H. (2010). Perceptions of institutional environment and entry mode. Management International Review, 50(2), 207-240. doi: 10.1007/s11575-010-0028-1

Demirbag, M., Tatoglu, E., \& Glaister, K. W. (2008). Factors affecting perceptions of the choice between acquisition and greenfield entry: the case of western FDI in an emerging market. Management International Review, 48(1), 5-38. doi: 10.1007/s11575-008-0002-3

Demirbag, M., Tatoglu, E., \& Glaister, K. W. (2009). Equity-based entry modes of emerging country multinationals: lessons from turkey. Journal of World Business, 44(4), 445-462. doi: 10.1016/j.jwb.2008.11.009

Dikova, D., \& Brouthers, K. D. (2009). Establishment mode choice: acquisition versus greenfield entry. In M. Kotabe \& K. Helsen (Eds.). The sage handbook of international marketing (pp. 218-237). Los Angeles, CA: Sage. 
Dikova, D., \& Witteloostuijn, A. van (2007). Foreign direct investment mode choice: entry and establishment modes in transition economies. Journal of International Business Studies, 38(6), 1013-1033. doi: 10.1057/palgrave.jibs.8400297

Dow, D., \& Larimo, J. (2009). Challenging the conceptualization and measurement of distance and international experience in entry mode choice research. Journal of International Marketing, 17(2), 74-98. doi: 10.1509/jimk.17.2.74

Drogendijk, R., \& Slangen, A. (2006). Hofstede, Schwartz, or managerial perceptions? The effects of different cultural distance measures on establishment mode choices by multinational enterprises. International Business Review, 15(4), 361-380. doi: 10.1016/j.ibusrev.2006.05.003

Erramilli, M. K., Agarwal, S., \& Kim, S. S. (1997). Are firm-specific advantages location-specific too? Journal of International Business Studies, 28(4), 735-757. doi: 10.1057/palgrave.jibs.8490117

Fink, A. (2005). Conducting research literature reviews: from the internet to paper. Thousand Oaks: Sage.

Gao, G. Y., Pan, Y., Lu, J., \& Tao, Z. (2008). Performance of multinational firms' subsidiaries: influences of cumulative experience. Management International Review, 48(6), 749-768. doi: 10.1007/s11575-008-0105-x

Gaur, A. S., \& Lu, J. W. (2007). Ownership strategies and survival of foreign subsidiaries: impacts of institutional distance and experience. Journal of Management, 33(1), 84-110. doi: $10.1177 / 0149206306295203$

Georgopoulos, A., \& Preusse, H. G. (2009). Cross-border acquisitions vs. greenfield investment: a comparative performance analysis in Greece. International Business Review, 18(6), 592-605. doi: 10.1016/j.ibusrev.2009.07.005

Guillén, M. F. (2003). Experience, imitation, and the sequence of foreign entry: wholly owned and jointventure manufacturing by South Korean firms and business groups in China, 1987-1995. Journal of International Business Studies, 34(2), 185-198. doi: 10.1057/palgrave.jibs.8400016

Haar, L. N., \& Marinescu, N. (2014). Entry modes and firm performance: evidence from inward FDI in Romania. Journal of East-West Business, 20(1), 44-56. doi: 10.1080/10669868.2013.862515

Harzing, A.-W. (2003). The role of culture in entry mode studies: from neglect to myopia? Advances in International Management, 15, 75-127. doi: 10.1016/S0747-7929(03)15006-8

Hennart, J. F. (1988). A transaction costs theory of equity joint ventures. Strategic Management Journal, 9(4), 361-374. doi: 10.1002/smj.4250090406

Hennart, J.-F. (1991). The transaction costs theory of joint ventures: an empirical study of Japanese subsidiaries in the United States. Management Science, 37(4), 483-497. doi: $10.1287 / \mathrm{mnsc} .37 .4 .483$

Hennart, J.-F., Kim, D.-J., \& Zeng, M. (1998). The impact of joint venture status on the longevity of Japanese stakes in U.S. manufacturing affiliates. Organization Science, 9(3), 382-395. doi: 10.1287/orsc.9.3.382

Hennart, J.-F., \& Larimo, J. (1998). The impact of culture on the strategy of multinational enterprises: does national origin affect ownership decisions? Journal of International Business Studies, 29(3), 515-538. doi:10.1057/palgrave.jibs. 8490005

Hennart, J. F., \& Park, Y. R. (1993). Greenfield vs. acquisition: the strategy of Japanese investors in the United States. Management Science, 39(9), 1054-1070. doi: 10.1287/mnsc.39.9.1054 
Ietto-Gillies, G. (2005). Transnational corporations and international production. Cheltenham: Edward Elgar Publishers.

Jung, J. C., Beamish, P. W., \& Goerzen, A. (2008). FDI ownership strategy: a Japanese-US MNE comparison. Management International Review, 48(5), 491-524. doi: 10.1007/s11575-008-0034-8

Katsikeas, C. S., Leonidou, L. C., \& Morgan, N. A. (2000). Firm-level export performance assessment: review, evaluation and development. Academy of Marketing Science, 28(4), 493-511. doi: $10.1177 / 0092070300284003$

Katsikeas, C. S., Leonidou, L. C., \& Samiee, S. (2009). Research into exporting: theoretical, methodological, and empirical insights. In M. Kotabe \& K. Helsen (Eds.), The sage handbook of international marketing (pp. 165-182). Los Angeles, CA: Sage.

Kaya, H., \& Erden, D. (2007). Assessing the performance of foreign equity ventures: the case of Turkish manufacturing FDI firms. Journal of Euromarketing, 16(4), 49-63. doi: 10.1300/J037v16n04_05

Kim, Y., \& Gray, S. J. (2008). The impact of entry mode choice on foreign affiliate performance: the case of foreign MNEs in South Korea. Management International Review, 48(2), 165-188. doi: $10.1007 / \mathrm{s} 11575-008-0010-3$

Kleinert, J., \& Toubal, F. (2010). Foreign sales strategies of multinational enterprises [Tübinger Diskussionsbeiträge n. 327], University of Tübingen, School of Business and Economics, Tübingen.

Kumar, V., \& Subramaniam, V. (1997). A contingency framework for the mode of entry decision. Journal of World Business, 32(1), 53-72. doi: 10.1016/S1090-9516(97)90025-0

Larimo, J. (2003). Form of investment by Nordic firms in world markets. Journal of Business Research, 56(10), 791-803. doi: 10.1016/S0148-2963(02)00467-8

Leung, W.-F. (1997). The duration of international joint ventures an foreign wholly-owned subsidiaries. Applied Economics, 29(10), 1255-1269. doi: 10.1080/00036849700000016

Li, J. (1995). Foreign entry and survival: effects of strategic choices on performance in international markets. Strategic Management Journal, 16(5), 333-351.

Li, J., \& Guisinger, S. (1991). Comparative business failures of foreign-controlled firms in the United States. Journal of International Business Studies, 22(2), 209-224.

Lin, H. (2000). Choice of market entry mode in emerging markets: influences on entry strategy in China. Journal of Global Marketing, 14(1/2), 83-109. doi: 10.1300/J042v14n01_05

López-Duarte, C., \& Vidal-Suárez, M. M. (2010). External uncertainty and entry mode choice: cultural distance, political risk and language diversity. International Business Review, 19(6), 575-588. doi: 10.1016/j.ibusrev.2010.03.007

Lu, J. W. (2002). Intra- and inter-organizational imitative behavior: institutional influences on Japanese firms' entry mode choice. Journal of International Business Studies, 33(1), 19-37. doi: 10.1057/palgrave.jibs.8491003

Luo, Y., \& Chen, M. (1995). Financial performance comparison between international joint ventures and wholly foreign-owned enterprises in China. Thunderbird International Business Review, 37(6), 599-613. doi: 10.1002/tie.5060370606

Madhok, A. (1998). The nature of multinational firm boundaries: transaction costs, firm capabilities and foreign market entry mode. International Business Review, 7(3), 259-290. doi: 10.1016/S09695931(98)00009-2 
Makino, S., \& Beamish, P. W. (1998). Local ownership restrictions, entry mode choice, and FDI performance: Japanese overseas subsidiaries in Asia. Asia Pacific Journal of Management, 15(2), 119-136. doi: 10.1023/A:1015481312926

Makino, S., \& Neupert, K. E. (2000). National culture, transaction costs, and the choice between joint venture and wholly owned subsidiary. Journal of International Business Studies, 31(4), 705-713. doi: 10.1057/palgrave.jibs. 8490930

Martin, X. (2013). Solving theoretical and empirical conundrums in international strategy research: linking foreign market entry mode choices and performance. Journal of International Business Studies, 44(1), 28-41. doi:10.1057/jibs.2012.29

Mata, J., \& Portugal, P. (2000). Closure and divestiture by foreign entrants: the impact of entry and postentry strategies. Strategic Management Journal, 21(5), 549-562. doi: 10.1002/(SICI)10970266(200005)21:5<549::AID-SMJ94>3.0.CO;2-F

Murray, J. Y, Ju, M., \& Gao, G. Y. (2012). Foreign market entry timing revisited: trade-off between market share performance and firm survival. Journal of International Marketing, 20(3), 50-64. doi: $10.1509 /$ jim. 12.0083

Mutinelli, M., \& Piscitello, L. (1998). The entry mode choice of MNEs: an evolutionary approach. Research Policy, 27(5), 491-506. doi: 10.1016/S0048-7333(98)00063-8

Nitsch, D., Beamish, P., \& Makino, S. (1996). Entry mode and performance of Japanese FDI in Western Europe. Management International Review, 36(1), 27-43.

Padmanabhan, P., \& Cho, K. R. (1996). Ownership strategy for a foreign affiliate: an empirical investigation of Japanese firms. Management International Review, 36(1), 45-65.

Padmanabhan, P., \& Cho, K. R. (1999). Decision specific experience in foreign ownership and establishment strategies: evidence from Japanese firms. Journal of International Business Studies, 30(1), 25-44. doi:10.1057/palgrave.jibs.8490059

Pak, Y. S., \& Park, Y. R. (2004). Global ownership strategy of Japanese multinational enterprises: a test of internalization theory. Management International Review, 44(1), 3-21.

Pan, Y., \& Tse, D. K. (2000). The hierarchical model of market entry modes. Journal of International Business Studies, 31(4), 535-554. doi:10.1057/palgrave.jibs.8490921

Pangarkar, N., \& Lim, H. (2003). Performance of foreign direct investment from Singapore. International Business Review, 12(5), 601-624. doi: 10.1016/S0969-5931(03)00078-7

Pennings, J. M., Barkema, H., \& Douma, S. (1994). Organization learning and diversification. Academy of Management Journal, 37(3), 608-640. doi: 10.2307/256702

Pla-Barber, J. (2001). The internalisation of foreign distribution and production activities: new empirical evidence from Spain. International Business Review, 10(4), 455-474. doi: 10.1016/S09695931(01)00026-9

Rajan, K. S., \& Pangarkar, N. (2000). Mode of entry choice: an empirical study of Singaporean multinationals. Asia Pacific Journal of Management, 17(1), 49-65. doi: 10.1023/A:1015484803666

Reus, T. H., \& Rottig, D. (2009). Meta-analyses of international joint venture performance determinants: evidence for theory, methodological artifacts and the unique context of China. Management International Review, 49(5), 607-640. doi: 10.1007/s11575-009-0009-4

Rocha, A. (2003). Por que as empresas brasileiras não se internacionalizam? In A. Rocha (Org.), As 
novas fronteiras: a multinacionalização das empresas brasileiras (pp.13-28). Rio de Janeiro: Mauad.

Rocha, A., \& Almeida, V. (2006). Estratégias de entrada e de operação em mercados internacionais. In B. Tanure \& R. G. Duarte (Orgs.), Gestão internacional (pp. 7-38). São Paulo: Saraiva.

Root, F. R. (1994). Entry strategies for international markets. New York: Lexington Books.

Ruiz-Moreno, F., Mas-Ruiza, F. J., \& Nicolau-Gonzálbez, J. L. (2007). Two-stage choice process of FDI: ownership structure and diversification mode. Journal of Business Research, 60(7), 795805. doi: 10.1016/j.jbusres.2007.02.013

Shaver, J. M. (1998). Accounting for endogeneity when assessing strategy performance: does entry mode choice affect FDI survival? Management Science, 44(4), 571-585.

Shaver, J. M. (2013). Do we really need more entry mode studies? Journal of International Business Studies, 44(1), 23-27. doi:10.1057/jibs.2012.24

Shi, Y.-Z. S., Ho, P.-Y., \& Siu, W.-S. (2001). Market entry mode selection: the experience of small Hong-Kong firms investing in China. Asia Pacific Business Review, 8(1), 19-41. doi: $10.1080 / 713999128$

Slangen, A. H. L., \& Hennart, J.-F. (2008b). Do foreign greenfields outperform foreign acquisitions or vice versa? An institutional perspective. Journal of Management Studies, 45(7), 1301-1328. doi: 10.1111/j.1467-6486.2008.00794.x

Slangen, A. H. L., \& Hennart, J.-F. (2008a). Do multinationals really prefer to enter culturally distant countries through greenfields rather than through acquisitions? The role of parent experience and subsidiary autonomy. Journal of International Business Studies, 39(3), 472-490. doi: 10.1057/palgrave.jibs.8400356

Slangen, A. H. L., \& Tulder, R. J. M. van (2009). Cultural distance, political risk, or governance quality? Towards a more accurate conceptualization and measurement of external uncertainty in foreign entry mode research. International Business Review, 18(3), 276-291. doi: 10.1016/j.ibusrev.2009.02.014

Sousa, C. (2004). Export performance measurement: an evaluation of the empirical research in the literature. Academy of Marketing Science Review, 4(9), 1-22. Recuperado de http://www.amsreview.org/articles/sousa09-2004.pdf

Tsai, M.-T., \& Cheng, Y.-M. (2002). The decision criteria for the ownership control entry mode for Taiwanese manufacturing firms in the United States: an application of the logit model and AHP. International Journal of Commerce and Management, 12(2), 45-71. doi: 10.1108/eb047443

Tsai, M. T., \& Cheng, Y. M. (2004). Asset specificity, culture, experience, firm size and entry mode strategy: Taiwanese manufacturing firms in China, South-East Asia and Western Europe. International Journal of Commerce and Management, 14(3/4), 1-27. doi: $10.1108 / 10569210480000181$

Tseng, C.-H., \& Lee, R. P. (2010). Host environmental uncertainty and equity-based entry mode dilemma: the role of market linking capability. International Business Review, 19(4), 407-418. doi: 10.1016/j.ibusrev.2010.03.002

Vermeulen, F., \& Barkema, H. G. (2001). Learning through acquisitions. Academy of Management Journal, 44(3), 457-476. doi: 10.2307/3069364 
Wang, H., \& Schaan, J.-L. (2008). How much distance do we need? Revisiting the "national cultural distance paradox". Management International Review, 48(3), 263-278. doi: 10.1007/s11575-0080015-y

Woodcock, C. P., Beamish, P. W., \& Makino, S. (1994). Ownership-based entry mode strategies and international performance. Journal of International Business Studies, 25(2), 253-273. doi: 10.1057/palgrave.jibs. 8490200

Xu, D., Pan, Y., \& Beamish, P. W. (2004). The effect of regulative and normative distances on MNE ownership and expatriate strategies. Management International Review, 44(3), 285-307.

Yiu, D., \& Makino, S. (2002). The choice between joint venture and wholly owned subsidiary: an institutional perspective. Organization Science, 13(6), 667-683. doi: 10.1287/orsc.13.6.667.494

Zejan, M. C. (1990). New ventures or acquisitions: the choice of Swedish multinational enterprises. Journal of Industrial Economics, 38(3), 349-355.

Zhao, H., \& Luo, Y. (2002). Product diversification, ownership structure, and subsidiary performance in China's dynamic market. Management International Review, 42(1), 27-48. 